\title{
CONTRIBUTIONS IN THE FIELD OF PUBLIC HEALTH FOR DECISION-MAKING IN HEALTH
}

Open acess

Doutorado no Instituto Fernandes Figueira |Fiocruz |RJ; Professor no curso de Pós-Graduação em Terapia Intensiva Neonatal (ESTIN) pela IPMED.

\section{Corresponding author:} latneves1@gmail.com

Manuscript received: 02 August 2017 Manuscript accepted: 25 August 2017 Version of record online: 06 September 2017

\author{
Luiz Antônio Tavares Neves
}

\begin{abstract}
Brazil has made a wide development and contribution in the field of Public Health. These contributions have maximized public health decision-making, which is a factor of great importance for the maintenance of health of a given population, either in the prevention of disease, as is the case of immunizations or with actions in Health Promotion, improving the quality of life of the affected population. Thus, the Journal of Human Growth and Development has contributed enormously to the dissemination of knowledge, not only in Brazil but also in the world making a major effort with its publications in English which is the preferred language of the modern scientific world. It was evidenced the importance of research in the investigation of better ways to obtain the public health of a given community, bringing discussion of themes that involve aspects of human growth and development such as nutritional aspects, sexuality, motor development, covering situations and diseases as obesity, cerebral palsy, dyslexia and violence. The Journal of Human Growth and Development has maintained the tradition of approaching the different aspects that involve clinical practice for people and for Public Health.
\end{abstract}

Keywords: knowledge, health, decision 
Brazil has made a wide development and contribution in the field of Public Health. These contributions have maximized decision-making in public health, which is a very important factor for the maintenance of health of a population in the prevention of disease, as is the case of immunizations or actions in Health Promotion, improving the quality of life of the affected population.

The Journal of Human Growth and Development has contributed enormously to the dissemination of knowledge, not only in Brazil, but also in the world, making a major effort with its publications in English, which is the preferred language of the modern scientific world. Several articles are included in the next issue that involve Public Health news with important themes; the central themes in human growth and development are highly valued, and since the establishment in 1990 has been the focus of the Journal of Human Growth and Development.

The authors address one of the most important issues in Public Health in modern times, the obesity. Obesity is the most prevalent nutritional disease in public health in children and adolescents in the United States, with approximately $21-24 \%$ of children being overweight and another $16-18 \%$ being obese, and the prevalence is higher among specific ethnic groups.

In one of the three studies to be published it is observed that the prevalence found in the capital of the Brazilian Western Amazon is similar to the American study. In the study carried out in Porto Velho, Amazon, Brazil, it was concluded that overweight presented high prevalence in A and B economic classes and in private schools. International data reported varied rates of obesity, however at least $10 \%$ of the children were overweight. Notably, however, the highest rates of obesity were found in Malta (22.4\%) and in the United States (25.4\%), which are highly industrialized countries ${ }^{1,2,3,4}$.

A recent study that addressed young Europeans suggests that Swedish children have the lowest risk of becoming obese in Europe. These studies are of great importance at the national level, since obesity in Brazil is already of great importance in the Public Health of Children and Adolescents and presents severe complications, that mainly include type 2 diabetes, hypertension, hyperlipidemia, bone maturation and accelerated growth, ovarian hyperandrogenism, cholecystitis, pancreatitis and pseudo-brain tumor. Long-term complications are due to a major association with childhood obesity and every effort should be made to treat it at this time of life, due to the chance of becoming an obese adult ${ }^{5,6}$.

The authors of this study point out in their conclusions that the practice of physical activity, associated with diet, should be stimulated, in addition to the reduction of sedentary behaviour. Oude et $a l^{7}$ concluded that although no program can be conclusively recommended, interventions in behaviour and lifestyle produce a significant reduction in body weight. Physicians and parents should encourage children to engage in vigorous physical activity throughout adolescence and adulthood, limiting the young individual to watch television and computer games for a fixed time, since even regular walks of 20-30 minutes can facilitate control of the weight.
In the same context, the study addresses the simultaneous presence of obesity and insufficient sleep hours in adolescents. This cross-sectional study focuses on one of the frequent complications of obesity and is considered an important risk factor for obesity with its full spectrum of complications ${ }^{8}$.

A well-balanced diet well quoted in the conclusions of the study on the lifestyle of children and adolescents is fundamental. They may be the most important factors, along with physical activity, both in preventing and controlling obesity. The World Health Organization ${ }^{9}$ has developed the following guidelines on food intake and sugar control:

For both adults and children, the World Health Organization recommends a reduction in sugar intake to less than $10 \%$ of the total amount of calories in 24 hours. It is important to note that this reduction should be lifelong. The reduction of free sugar, which is those sugars added to beverages, artificial fruit juices and sweets etc., is vital in the prevention of obesity in children and adolescents.

Prematurity, especially for new-borns with extremely low birth weight, has been associated with obesity when they reach the stage of childhood and adolescence, its fearsome complication as the metabolic syndrome ${ }^{10}$. A high body mass index in the pregnant woman puts her at risk for perinatal outcomes and among them, they present a greater chance of immediate complications, such as caesarean section and large bleeding and maternal intercurrences, like gestational diabetes and hypertensive syndrome, as well as perinatal asphyxia ${ }^{11}$.

Recent information suggest that low birth weight is an important variable for the occurrence of obesity and components related to the metabolic syndrome, and that these changes can be detected early in childhood and adolescence. Some factors related to the fetus and the mother are mentioned in the literature as triggers of prematurity and subsequent low birth weight. Individuals with low gestational age have a high risk of rapid postnatal weight gain, late obesity, and some metabolic syndrome processes such as type 2 diabetes, dyslipidaemia, hypertension and cardiovascular disease. Knowing the panorama of these conditions could contribute to an early attention to the health of the child with a history of low birth weight with risks to the programming for these diseases in the long term ${ }^{12,13}$.

Over the last years, the association between the improvement on human neuropsychomotor development with breastfeeding, especially in premature born. This study, that focus on the development of infants in the north-eastern Brazilian region, is about the extraordinary importance of exclusive infant feeding up to 6 months of life. Despite its complexity, it is very clear that the mother's own milk is better even for those of extremely low birth weight, both short-term protection against sepsis, necrotizing and long-term enterocolitis for cognitive outcomes $^{14}$.

In addition, fortification of human expressed milk seems to be safe to compensate for the intake of deficient energy or insufficient nutrients ${ }^{15}$. Recently, the main advances are in relation to the best time and how much to feed and the importance of feeding very early with 
maternal colostrum ${ }^{16}$. Now it is known that it is possible to feed even at very early births thanks to the education of the nurses, maternal support and supervised expression. The majority of nutritional studies in infants weighing less than $1.000 \mathrm{~g}$ reinforce the concept that initiating early enteral feeding reduces parenteral feeding time, decreases length of hospital stay and allows better weight gain during discharge. It is vital, therefore, that maternal nutrition is unique and continues until the sixth month of life.

The current study of predictive models of adequate motor development in preterm infants draws attention to the responsibility of those working with neurodevelopment. Early adequate motor development has always been the ultimate goal of parents and the team of specialists working with child development, such as physiotherapists, nurses, neonatologists, psychologists, and related professionals. The care with proper motor development begins with serious antenatal care based on international standards. The use of drugs such as corticosteroids, magnesium sulfate and aggressive tocolise moments before delivery is vital to protect from diseases that may cause brain damage and prevent adequate neurodevelopment ${ }^{17,18}$. Follow-up is always necessary to detect early neuropsychomotor changes and correct them if possible.

Two studies address the issue of Cerebral Palsy, which is the main sequel for infants born at birth weighing less than 1,500 $\mathrm{g}$ and for those suffering HypoxicIschemic encephalopathy at birth. Cerebral Palsy is the leading cause of school-age disability, affecting both function and development. The incidence of this condition has not changed much in the last four decades, despite the great scientific technical advance of neonatal care. Brain lesions of cerebral palsy occur from the fetal or neonatal period and may extend for more than three years ${ }^{19,20}$. It is important to note that $30-50 \%$ of patients with cerebral palsy present mental retardation. However, due to gross, fine and motor difficulties, communication in these infants may be impaired and the expression of intellectual capacity will be limited. So if Cerebral Palsy is treated in a multidisciplinary way with nutritional, occupational, and physical therapy to maximize rehabilitation efforts, patients can be more academically and socially integrated $^{21,22}$.
The family participation, very well characterized in the studies to be published, is of fundamental importance, as well as the provision of resources. Since several patients have severe difficulty locomotion, the wheelchair may be useful. Orthoses are often required to maintain the position of the functional joint at the lower and upper extremities especially in hemiplegic patients. The treatment associated with cerebral palsy aims to improve the interaction between the caregiver and the infant, providing family support, providing resources, and promoting parental education as well as promoting motor training and skills development ${ }^{23,24}$.

Finally, an important study showing the characteristics of sexual abuse in Santo André, São Paulo, Brazil, describes the social demographic characteristics of the victims, as well as of the aggressors, making an important contribution in relation to sexual violence in our environment. Children suspected of having suffered sexual aggression need a general medical, behavioral, social and gynecological history. A family and social history is vital to the knowledge of the environment in which the abuse occurred. Generally girls experience more sexual violence in a ratio of 1 to 4 while boys experience sexual violence around 1 to $6^{25}$.

After sexual violence, the child is extremely vulnerable and may experience changes in eating, suicidal behavior, self-injury and psychosis. They may also be at increased risk for reabsorption. Very often the attacker may be very close to the environment in which the child lives. In the United States, about 83,550 children were sexually abused in 2005, showing that this is a serious public health problem ${ }^{26,27}$.

The importance of research that can investigate better ways to promote the public health to the community and also transfer of knowledge is fundamental. The Journal of Human Growth and Development maintains the tradition of approaching the different aspects that involve clinical practice for people and Public Health.

\section{REFERENCES}

1. Farias ES, Santos JP, Soares MM, Moreira KFA, Gemelli IFB, Gonçalves LGO, et al. Fatores associados ao excesso de peso em uma amostra populacional de adolescentes escolares. J Hum Growth Dev. 2017;27(2):56-63. DOI: http://dx.doi.org/10.7322/jhgd.10000

2. Pi-Sunyer FX. The obesity epidemic: pathophysiology and consequences of obesity. Obes Res. 2002;10(Suppl 2):97S-104. DOI: http://dx.doi.org/10.1038/oby.2002.202

3. World Health Organization (WHO). Obesity: preventing and managing the global epidemic. Geneva: WHO; 2000

4. Aliyu MH, Luke S, Wilson RE, Saidu R, Alio AP, Salihu HM, et al. Obesity in older mothers, gestational weight gain, and risk estimates for preterm phenotypes. Maturitas. 2010;66(1):88-93. DOI: http://dx.doi. org/10.1016/j.maturitas.2010.02.016

5. Shomaker LB, Tanofsky-Kraff M, Zocca JM, Field SE, Drinkard B, Yanovski JA. Depressive symptons and cardiorespiratory fitness in obese adolescentes. J Adoles Health. 2012;50(1):87-92. DOI: http:// dx.doi.org/10.1016/j.jadohealth.2011.05.015

6. Inge TH, King WC, Jenkins TM, Courcoulas AP, Mitsnefes M, Flum DR, et al. The effect of obesity in adolescence on adult health status. Pediatrics. 2013; 132(6):1098-104. 
DOI: http://dx.doi.org/10.1542/peds.2013-2185

7. Oude Luttikhuis H, Baur L, Jansen H, Shrewsbury VA, O'Malley C, Stolk RP, et al. Interventions for treating obesity in children. Cochrane database Syst Rev. 2009;(1):CD001872.

DOI: http://dx.doi.org/10.1002/14651858.CD001872.pub2

8. Archbold KH, Vasquez MM, Goodwin JL, Quan SF. Effects of sleep patterns and obesity on increase in blood pressure in a 5 year period: report from Tucson Children's Assesssment of Sleep Apnea Study. J Pediatr. 2012; 161(1):26-30. DOI: http://dx.doi.org/10.1016/j.jpeds.2011.12.034

9. World Health Organization (WHO). Guideline: sugars intake for adults and children. Geneva: WHO; 2015.

10. Iliadou A, Cnattingius S, Lichtenstein P. Low birth weight and type 2 diabetes: a study on 11162 Swedish twins. Int J Epidemiol. 2004;33(5):948-53. DOI: http://dx.doi.org/10.1093/ije/dyh117

11. Sawaya AL. Desnutrição: consequências em longo prazo e efeitos da recuperação nutricional. Estudos Av. 2006;20(58):147-58. DOI: http://dx.doi.org/10.1590/S0103-40142006000300016

12. Young N, Goldstein RF, Bann CM, Hintz SR, Patel RM, Smith PB, et al. Survival and Neurodevelopmental Outcomes among Periviable Infants. N Engl J Med. 2017;376:617-28. DOI: http://dx.doi.org/10.1056/NEJMoa1605566

13. Lima TR, Sousa GR, Castro JAC, Silva DAS. Simultaneous presence of excess weight and insufficient hours of sleep in adolescents: prevalence and related factors. J Hum Growth Dev. 2017; 27(2):148-157. DOI: http://dx.doi.org/10.7322/jhgd.115987

14. Severiano AAO, Dantas DS, Oliveira VLC, Lopes JM, Souza DS, Magalhães AG. Association between breastfeeding, obstetric factors and child development in northeast brazil. J Hum Growth Dev. 2017;27(2):158-165. DOI: http://dx.doi.org/10.7322/jhgd.114483

15. Smith H, Embleton ND. Improving expressed breast milk (EBM) provision in the neonatal unit: A rapid and effective quality improvement (QI) intervention. J Neonatal Nurs. 2013;19(4):149-53. DOI: https://doi.org/10.1016/j.jnn.2013.02.001

16. Leaf A, Dorling J, Kempley S, McCormick K, Mannix P, Linsell L, et al. Early or delayed enteral feeding for preterm growth-restricted infants: a randomized trial. Pediatrics. 2012;129: e1260-8. DOI: https://doi.org/10.1542/peds.2011-2379.

17. Formiga CKMR, Vieira MEB, Fagundes RR, Linhares MBM. Predictive models of early motor development in preterm infants: a longitudinal-prospective study. J Hum Growth Dev. 2017; 27(2): 189197. DOI: http://dx.doi.org/10.7322/jhgd.111288

18. Volpe JJ. Hypoxic-Ischemic encephalopathy. In: Volpe JJ.Neurology of the Newborn. vol 899. Elsevier; 2008; p.245-400.

19. Morilla CM, Caldas CACT, Scarpellini ACAV, Santos PL. Family resources and promotion of development of children with cerebral palsy. J Hum Growth Dev. 2017; 27(2): 166-174. DOI: http://dx.doi.org/10.7322/jhgd.122707

20. Andrade MMG, Elpídio de Sá F, Frota LMCP, Cardoso KVV Carleial GMA. Interventions of health education in mothers of children with cerebral palsy. J Hum Growth Dev. 2017; 27(2):175-181. DOI: http://dx.doi.org/10.7322/jhgd.126857

21. Odding E, Roebroeck ME, Stam HJ. The epidemiology of cerebral palsy: incidence, impairments and risk factors. Disabil Rehabil. 2006;28(4):183-91. DOI: https://doi.org/10.1080/09638280500158422

22. Russman BS, Ashwal S. Evaluation of the child with cerebral palsy. Semin Pediatr Neurol. 2004;11(1):4757. DOI: https://doi.org/10.1016/j.spen.2004.01.007

23. Mayston MJ. People with cerebral palsy: effects of and perspectives for therapy. Neural Plast. 2001;8(12):51-69. DOI: https://doi.org/10.1155/NP.2001.51

24. Mattren-Baxter K. Effects of partial body weight suported tredmill training on children with cerebral palsy. Pediatr Phys Ther. 2009;21(1):12-22. DOI: https://doi.org/10.1097/PEP.0b013e318196ef42

25. Chehab MAD, Paiva LS, Figueiredo FWS, Daboin BEG, Reato LFN, Adami F. Sexual abuse characteristics in Santo André, São Paulo, Brazil: from victims to aggressors, from diagnosis to treatment. J Hum Growth Dev. 2017; 27(2): 228-234. DOI: http://dx.doi.org/10.7322/jhgd.123611

26. Castro JFL, Araújo RC, Pitangui ACR. Sexual behavior and practices of adolescent students in the city of Recife, Brazil. J Hum Growth Dev. 2017; 27(2): 219-227. DOI: http://dx.doi.org/10.7322/jhgd.112645

27. Nobre FSS, Bandeira PFR, Valentini NC. Academic achievement associated with motor performance and sex in diifferents subcultures. J Hum Growth Dev. 2017; 27(2): 213-218. DOI: http://dx.doi.org/10.7322/jhgd.115027 